\title{
Comparison of traditional and optical grain-size field measurements with SNOWPACK simulations in a taiga snowpack
}

\author{
L. LEPPÄNEN, A. KONTU, J. VEHVILÄINEN, J. LEMMETYINEN, J. PULLIAINEN \\ Arctic Research Centre, Finnish Meteorological Institute, Sodankylä, Finland \\ Correspondence: L. Leppänen <leena.leppanen@fmi.fi>
}

\begin{abstract}
Knowledge of snow microstructure is relevant for modelling the physical properties of snow cover and for simulating the propagation of electromagnetic waves in remote-sensing applications. Characterization of the microstructure in field conditions is, however, a challenging task due to the complex, sintered and variable nature of natural snow cover. A traditional measure applied as a proxy of snow microstructure, which can also be determined in field conditions, is the visually estimated snow grain size. Developing techniques also allow measurement, for example, of the specific surface area (SSA) of snow, from which the optical-equivalent grain size can be derived. The physical snow model SNOWPACK simulates evolution of snow parameters from meteorological forcing data. In this study we compare an extensive experimental dataset of measurements of traditional grain size and SSA-derived optical grain size with SNOWPACK simulations of grain-size parameters. On average, a scaling factor of $\mathbf{1 . 2}$ is required to match traditional grain-size observations with the corresponding SNOWPACK simulation; a scaling factor of 2.1 was required for the optical equivalent grain size. Standard deviations of scaling factors for the winters of 2011/12 and 2012/13 were 0.36 and 0.42 , respectively. The largest scaling factor was needed in early winter and under melting conditions.
\end{abstract}

KEYWORDS: remote sensing, snow, snow metamorphosis, snow physics

\section{INTRODUCTION}

In the Northern Hemisphere, observation of seasonal snow cover is essential to, for example, climate change monitoring, flood forecasting and avalanche warning systems (e.g. Martinec and Rango, 1986; Brown, 2000; Mognard, 2003; Shaffrey and others, 2009). Snow microstructure is important for physical modelling of snow evolution and remote-sensing algorithms. Grain size is a critical parameter in the analysis of snowpack development and metamorphism (Colbeck, 1982). It is also used as a proxy of snow microstructure in many remote-sensing applications (Tsang and others, 1985; Pulliainen and others, 1999).

Global mapping of snow cover is possible with optical and microwave satellite instruments (e.g. Hall and others, 2002). The extent of the snow-covered area can be observed by using visual and near-infrared wavelengths (e.g. Hall and others, 1995; Maurer and others, 2003), and snow water equivalent (SWE) can be determined from passive microwave measurements (e.g. Chang and others, 1982; Pulliainen and Hallikainen, 2001). Radiative transfer models are used to simulate microwave radiation from experimental measurements, and model inversion can be applied in retrieval of snow parameters from microwave observations. Among other snow parameters, snow emission models use grain size (Tsang and others, 1985; Pulliainen and others, 1999) or correlation length (Tsang and Kong, 1981; Stogryn, 1986; Wiesmann and others, 1998; Wiesmann and Mätzler, 1999) to describe the effect of snow microstructure on microwaves. The models are very sensitive to changes in the parameter describing the microstructure; thus its parameterization has a direct impact on the accuracy of the inverted SWE (e.g. Grenfell and Warren, 1999; Mätzler and Wiesmann, 1999; Roy and others, 2004).

Natural snowpacks consist of morphologically different layers (Colbeck, 1991); layers have typically distinct grain size, grain type, density, hardness and wetness. Several methods of defining the snow microstructure have been presented. The physical size of snow grains $(E)$ is traditionally defined visually as the largest diameter $(\mathrm{mm})$ of a typical particle (Colbeck and others, 1990; Fierz and others, 2009). However, an acknowledged problem concerning $E$ is that it is difficult to define and measure with good repeatability in field conditions (e.g. Domine and others, 2006). Baunach and others (2001) present a comparison of $E$ estimations made by several experts; the difference in estimation of $E$ varied between 0.25 and $1.25 \mathrm{~mm}$. Estimations were closest when grains were at an early stage of metamorphosis, i.e. grains were quite small and round. Other measures of individual grains more descriptive of the microwave behavior have been proposed by, for example, Mätzler (2002).

The optical grain size $\left(D_{0}\right)$, on the other hand, is defined as the diameter of independent spheres that have the same optical hemispherical reflectance properties as the snow, and which are proportional to the volume-surface ratio of the grains (Giddings and LaChapelle, 1961; Wiscombe and Warren, 1980; Dozier and others, 1987; Grenfell and Warren, 1999). Therefore, $D_{0}$ is not the same as $E$ of a particle, with the exception of material consisting of perfect spheres (Wiscombe and Warren, 1980). Theoretical correlation length, on the other hand, describes the distribution of scattered radiation, and is related to grain size, shape and volumetric distribution of snow grains (e.g. Debye and others, 1957; Jin, 1993). However, three-dimensional measurements of the correlation length are difficult.

The physical snow evolution model SNOWPACK (Lehning and others, 2002a) can be used to simulate the evolution of different characteristics of snow. Simulation of $E$ is not a simple process, because the physical processes are variable and the shapes of snow crystals are complex; therefore, several equations and semi-empirical parameterizations are 
needed. In the non-dendritic case, when grains are not branched, $D_{0}$ is dependent on $E$. Independent equations are applied for the dendritic branched grains.

$D_{0}$ can be derived from specific surface area (SSA) measurements. SSA is a geometrical characteristic of porous sintered materials such as snow, and is related to chemical, physical and electromagnetic properties of the medium (Grenfell and Warren, 1999; Domine and others, 2008; Matzl and Schneebeli, 2010). SSA can be measured by stereology (e.g. Matzl and Schneebeli, 2010), X-ray computed microtomography (Flin and others, 2005; Chen and Baker, 2010), the methane adsorption method (Domine and others, 2001; Legagneux and others, 2002) and optical methods (Matzl and Schneebeli, 2006; Painter and others, 2007; Gallet and others, 2009; Langlois and others, 2010; Arnaud and others, 2011). Reflectance, and therefore optically measured SSA, also depends on grain shape (Picard and others, 2009). In this study, SSA was measured with the optical reflectance method presented by Gallet and others (2009).

The aim of the presented research was to: (1) compare in situ measured values to those modelled using the SNOWPACK thermodynamic snow model and (2) investigate the source and magnitude of measurement errors related to these parameters.

\section{THEORY AND MEASUREMENT METHODS}

\section{Grain growth}

The shape and size of ice particles (referred to as snow grains from now on) change throughout the winter. Growth of snow grains is caused by changes in ambient physical conditions (Adams and Brown, 1982; Colbeck, 1982); the strongest effects are caused by changes in temperature and density.

Temperature differences in the snowpack are related to differences in air temperature, thermal conductivity of snow, terrain, vegetation, elevation and the amount of sunlight. Land-cover type affects the structure of the snowpack (e.g. an ice layer over a bog forms a different base for the snowpack than dry ground). Furthermore, even if the ambient temperature remains stable, the snowpack exhibits a vertical temperature gradient in conditions where the ambient and subnivean temperatures differ because of the low thermal conductivity of snow. Changes in snow density are also induced by temperature changes; however, the snowpack also compacts at constant temperatures, new snow increases the pressure in the older snow, and density of the snow increases.

Changes in temperature and density affect the state of grain metamorphism in the snowpack. Generally, metamorphism drives the formation of different grain shapes (Fierz and others, 2009). Colbeck (1982) describes grain shape changes through the winter; grains can form again several times, and a rule of thumb is that the average size of snow grains increases with age and depth of snowpack.

\section{Snow class definitions}

Snow grains can be classified by shape. In this paper, definitions following Fierz and others (2009) are used: grain classifications include precipitation particles (PP), decomposing and fragmented precipitation particles (DF), rounded grains (RG), faceted crystals (FC), depth hoar (DH), melt forms (MF) and ice formations (IF).
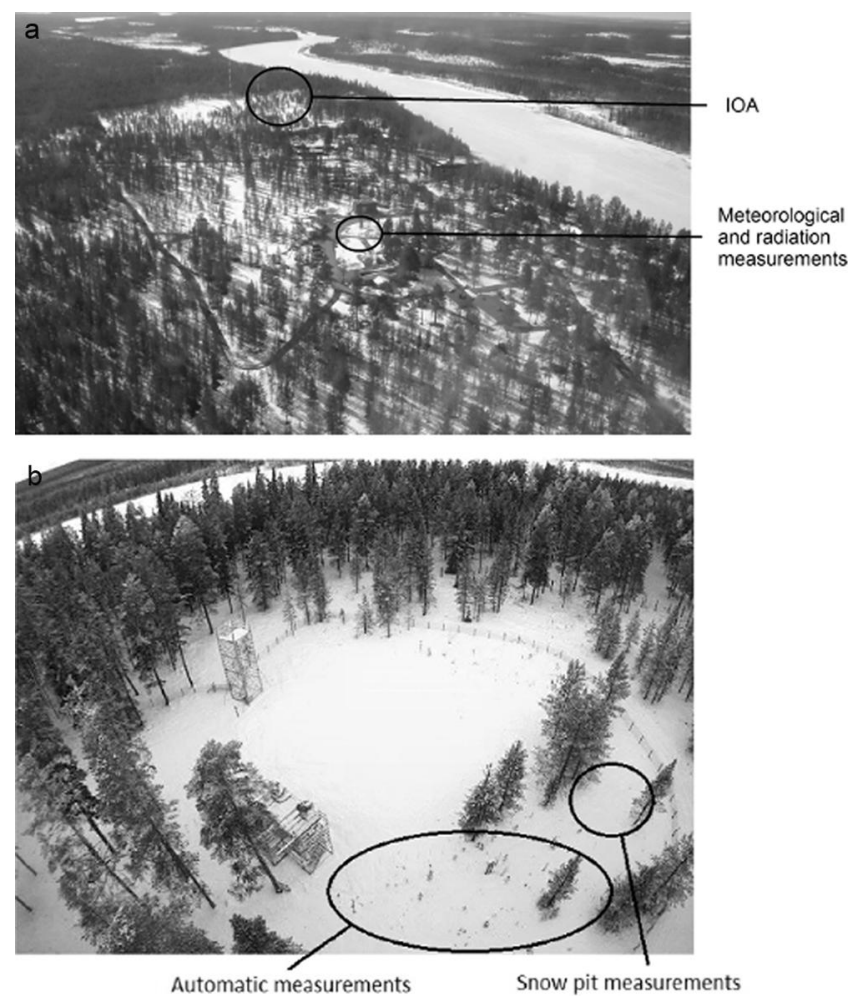

Fig. 1. (a) Aerial photograph of the Sodankylä facilities. IOA is the intensive operation area. Meteorological and radiation measurements, used to force the SNOWPACK model, were made $500 \mathrm{~m}$ from IOA in a similar environment. (b) The measurement field covered with snow on a natural forest floor.

\section{Measurement site}

Snow profiles were measured at the Arctic Research Centre of the Finnish Meteorological Institute (FMI), Sodankylä, northern Finland, $\left(67.368^{\circ} \mathrm{N}, 26.633^{\circ} \mathrm{E}\right)$ over two snow seasons. Measurements were made between January 2012 and April 2013. The measurement site (IOA (intensive observation area)) was located in a clearing surrounded by a sparse pine forest (Fig. 1). The site hosted several automated measurements (e.g. snow temperature profile, soil temperature profile, soil moisture and SWE). The meteorological and radiation data used for modelling were measured at a distance of $500 \mathrm{~m}$ from the $\mathrm{IOA}$, where surroundings were similar to the IOA.

Snow cover at the site persists on average for 200 days, between the end of October and the end of May (Pirinen and others, 2012). The thermal winter, when the daily average temperature falls below zero, typically begins near the end of September and ends near the end of May. The maximum amount of snow is, on average, $80 \mathrm{~cm}$ in March, followed by a snowmelt period lasting until May. For the two winter seasons (2012 and 2013) used in this research, the measured snow depth and temperature profiles are presented in Figure 2.

The seasonal snowpack in Sodankylä has large variations in grain size and density, and impurities from, for example, tree litter and inorganic soot. Vertical layering caused by weather effects is inherent in snowpacks; however, natural snow also exhibits a high degree of horizontal variability in layering and snow structure caused by wind, vegetation and terrain effects (Sturm and others, 1998). In the case of new snow, the surface of the 


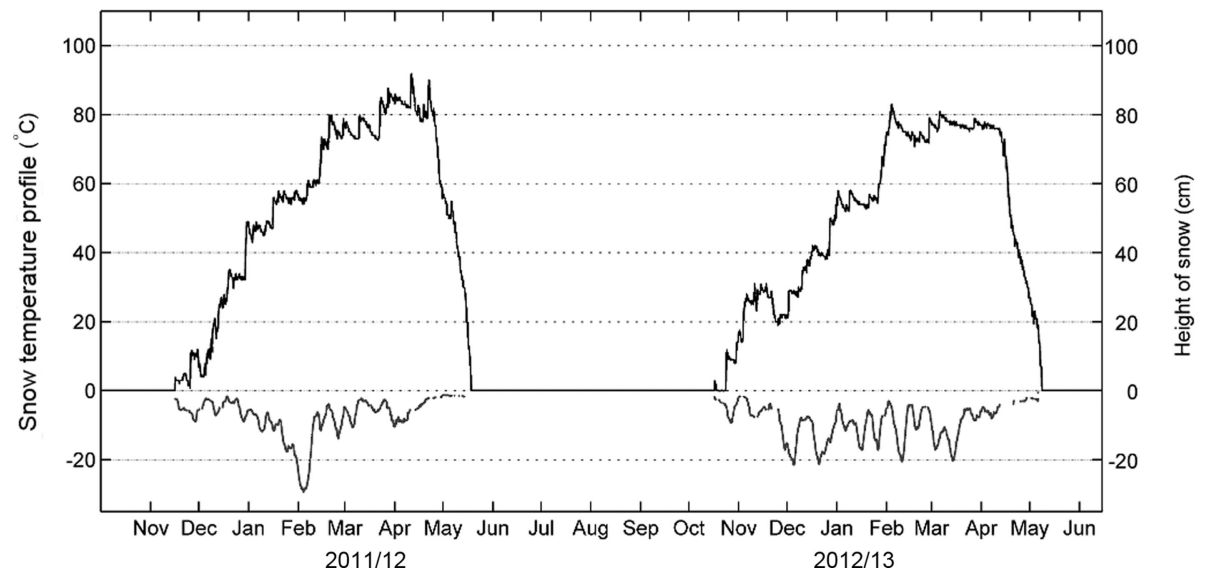

Fig. 2. Height of snow (upper, black curves) and temperature profile (difference of temperature at surface and base) of snowpack (lower, grey curves) during winters 2011/12 and 2012/13.

snowpack is typically light, and new snowflakes are large and dendritic. For older snowpacks, densification typically increases towards the bottom layers. In the middle of the snowpack, snow grains are smaller and rounder than in the surface layers. Grain size further increases towards the ground; near the ground, snow consists of grains with a large range of different sizes. During winter, the thickness of the bottom layer (mostly DH crystals) increases, the proportion of small and large grains changes, and the proportion in the layer increases near ground. The structure of the snowpack varies annually, in particular as a function of the temperature gradient over the snowpack (between air and soil temperatures).

The most common grain shapes in Sodankylä are PP, DF, RG, FC, DH and MF. Occasionally over the winter, SH crystals occur. Melting and recrystallization of the surface snow during a warm period, followed by a cold period, creates a hard crust layer, which is classified as MFcr or sometimes as IF.

The average grain-size value for the whole snowpack was considered appropriate when analysing the time series of snowpack evolution. As snow pits are forcibly made at a different location each time, the dataset at hand encompassed both temporal and spatial variations in snow structure, which are difficult to separate from one another. A weighted average was calculated to alleviate the effects of spatial (horizontal) variability of grain size in the snowpack. As the propagation of electromagnetic radiation in snow is closely related to the SWE (depth $\times$ density), weighting with SWE gives a better proxy of the relative weight of the grain size in each layer in terms of microwave interactions, compared to simple depth-weighted averaging. Other methods include weighing the grain size of each layer by the assumed optical depth of respective overlying layers (e.g. Tedesco and Kim, 2006).

\section{Snow-pit measurements}

The research was based on manual snow-pit measurements made over the 2011/12 and 2012/13 winter seasons. The collected data include estimates of $E$ as well as SSA measurements. SSA was measured with a commercial IceCube instrument (Gallet and others, 2009). Grain-size measurements of $E$ were performed by visually analysing macro-photographs of grain samples against a reference grid. Automated meteorological and radiation data from the test site were used to drive the SNOWPACK model; model estimates of $E$ and $D_{0}$, given as $E_{\mathrm{spi}}$ and $D_{0 \mathrm{sp}}$, aggregated over the snowpack to improve comparability, were analysed against the in situ measurements. The different grain-size parameters are presented in Table 1.

The collected dataset includes 35 snow-pit measurements, made over the two winters. Typically, the snow pits were measured at 1 week intervals. However, several extra measurements were arranged. Due to the destructive nature of the measuring process, the exact location of the snow pit changed each time; new pits were made at a minimum distance of $1 \mathrm{~m}$ from previous pits to avoid changes in snow structure caused by previous pit measurements. The data thus also include the effect of small-scale spatial variability, in addition to temporal variability caused by weather events and snow metamorphism.

All measurements from a snow pit were taken from a vertical cut of $\sim 50 \mathrm{~cm}$ width made in the snowpack. Layers were determined manually from the snow-pit wall by changes in snow structure (e.g. density, hardness, grain size and shape). The measured snow-pit data include snow layer thicknesses, $E$ for each layer, temperature profile (every $10 \mathrm{~cm})$, density profile measured by weighting a snow sample (every $5 \mathrm{~cm}$ ), and SSA measurements (every $3 \mathrm{~cm}$ ). However, reliable density and SSA measurements from $5-10 \mathrm{~cm}$ above ground level were not always possible due to hard packed or very coarse-grained snow.

Table 1. Grain-size definitions

\begin{tabular}{|c|c|c|}
\hline Grain size & Symbol & Description \\
\hline Traditional & $E$ & $\begin{array}{c}\text { The classical grain size of a snow } \\
\text { layer is the average size of its grains. } \\
\text { The largest extension of a grain is } \\
\text { measured in mm. }\end{array}$ \\
\hline Optical & $D_{0}$ & $\begin{array}{l}\text { Diameter of optically equivalent ice } \\
\text { spheres which have the same } \\
\text { optical properties (surface-to-volume } \\
\text { ratio) as original particles. Derived } \\
\text { from the reflectance measurements } \\
\text { made with the IceCube instrument. }\end{array}$ \\
\hline SNOWPACK traditional & $E_{\mathrm{sp}}$ & Simulated with SNOWPACK model. \\
\hline SNOWPACK optical & & Simulated with SNOWPACK model. \\
\hline
\end{tabular}



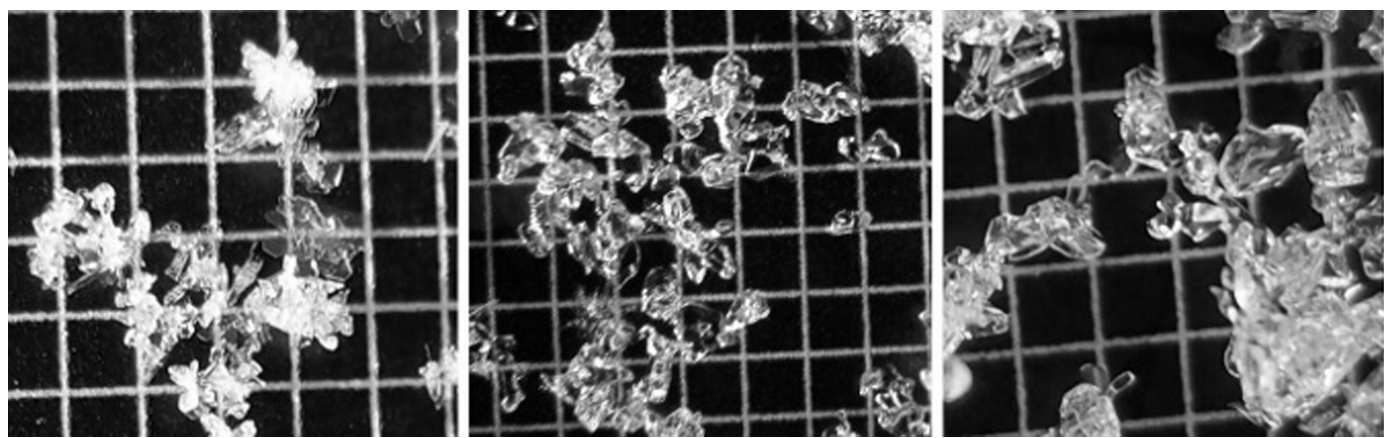

Fig. 3. Macro-photographs taken against a $1 \mathrm{~mm}$ reference grid in Sodankylä. Examples of dendritic (left) and non-dendritic (middle) grains. Grain shape in the left panel is PPsd, in the middle panel RGxf and in the right panel right FCxr. Grain size exhibits large variability in the right panel, likely causing observer-related bias. Grain size is more uniform in the other two photographs.

E was estimated visually for each snow layer by comparing snow grains to a $1 \mathrm{~mm}$ reference grid. The methodology differed from the traditional measurement (Fierz and others, 2009), because estimation was made during post-processing from macro-photographs. Occasionally, layers contained very hard snow and grains, and could not be distinguished without breaking the snow structure. Some of the photographs were also of low quality, so the grain-size estimation could not be made. Only one snow sample was taken from each layer, so errors in the definition of snow layers may have affected the representativity of the results. $E$ was recorded to the nearest $0.25 \mathrm{~mm}$. Photographs of different types of grains are presented in Figure 3. The snow type was determined visually from the same macro-photographs.

\section{SSA measurements}

A novel method of measuring $D_{0}$, the diameter of opticalequivalent ice spheres, is to derive it from measurements of reflectance (Gallet and others, 2009). SSA $\left(\mathrm{m}^{2} \mathrm{~kg}^{-1}\right)$ is defined as the surface area of particles per unit mass:

$$
\mathrm{SSA}=S / M=S /\left(\rho_{\mathrm{i}} V\right),
$$

where $S$ is surface area, $M$ is mass of the sample, $\rho_{\mathrm{i}}$ is the density of ice $\left(917 \mathrm{~kg} \mathrm{~m}^{-2}\right)$ and $V$ is volume of the sample (Legagneux and others, 2002). The optical diameter of ice spheres is presented by Kokhanovsky and Zege (2004) as

$$
D_{0}=6 \mathrm{~V} / \mathrm{S} \text {. }
$$

The theoretical relation between $D_{0}$ and SSA from Eqns (1) and (2) is

$$
D_{0}=6 /(\rho \mathrm{SSA}) \text {. }
$$

The SSA decreases with increasing grain size, as there is more empty space between large grains than between smaller grains.

For SSA measurements, we used the IceCube manufactured by A2 Photonic Sensors, France, which is a commercial single-frequency instrument similar to DUFISSS (Gallet and others, 2009). The instrument measures the hemispherical infrared reflectance of the snow samples, which can be linked to SSA (e.g. Domine and others, 2006; Matzl and Schneebeli, 2006). The whole snowpack was sampled at $3 \mathrm{~cm}$ intervals; the measurements were made from the same cut in the snowpack (i.e. pit) as the $E$ estimations.

IceCube measurements consisted of calibration measurements and measurements of snow samples. The surface of the sample had to be smooth for the measurement to succeed; ice layers and very hard snow layers were difficult to measure, and several measurements were omitted as a result. Moreover, large crystals at the bottom of the snowpack proved difficult to sample correctly, so these measurements may carry additional errors. The sample also had to be compacted in the sample holder to avoid absorption of radiation at the bottom of the holder, which obscures reflections from the snow sample. For clustered grains (e.g. $\mathrm{MFCl}$ or MFpc), the SSA value was smaller, because grains were closer to each other than free grains of the same size would be (Dozier and Painter, 2004). During the measurement the sample holder was set below the instrument. Calibration measurements of the IceCube were made before and after every measurement occasion. The calibration result depended on, for example, the laser temperature, the cleanness of the spectralon surfaces and the mechanics of the instrument. The IceCube was calibrated by measuring the reflectances of six different spectralon plates and the background radiation. A least-squares polynomial was fitted to these seven measurements, and the success of the calibration was determined from the fit. The programme gives the user an estimate of the quality of the calibration from the success of the curve fit, by using a scale of very poor, poor, good and excellent. Error estimation of calibration is important, because the success of the calibration was not seen during measurement and some of the calibration measurements were often of poor quality. Errors may have originated from any single calibration measurement or multiple calibration measurements. Theoretically, it was also possible for all calibration measurements to be shifted systematically to the same direction to indicate good calibration, but the magnitude of the result (signal-toreflectance relationship) would then be erroneous.

\section{Snowpack model}

SNOWPACK is a one-dimensional (1-D) physically based finite-element model developed at the WSL Institute for Snow and Avalanche Research SLF, Switzerland. The characteristics of the numerical set-up, the microstructure and the initial and driving parameters of the model are described by Lehning and others $(2002 a, b)$. The number of individual layers in the model is not restricted, and increases in response to snow precipitation.

SNOWPACK simulates three types of snow metamorphism: equilibrium metamorphism, temperature gradient metamorphism and wet snow metamorphism. Only the first two metamorphism simulations were investigated in this study. 
The snow grains are parameterized using size parameters (grain size and bond size) and shape parameters (dendricity and sphericity). The sphericity describes the ratio of rounded versus faceted shapes, and the dendricity describes the part of original grain shapes that remain in a snow layer. Both parameters vary from 0 to 1 . The dendricity and sphericity were set to 1 and 0.5 , respectively, for new snow. In old rounded snow grains, the dendricity decreases to zero. The shape parameters are based on the French snow model Crocus. Further details can be found in, for example, Brun and others (1992).

Grain growth and thus grain size $\left(E_{\mathrm{sp}}\right)$ is defined by several equations in the SNOWPACK model depending on the physical conditions in the snowpack. The grain growth during equilibrium metamorphism, as the temperature gradient is small, is based on a mixture theory model described by Brown and others $(1999,2001)$. $E_{\mathrm{sp}}$ during equal temperature metamorphism is the diameter of a sphere. The grain growth rate $\left(r_{\mathrm{g}}\right)$ is presented by Lehning and others (2002b) in the equal temperature metamorphism as

$$
\dot{r}_{\mathrm{g}}(T, t)=s\left(A_{1}+\frac{A_{2}}{r_{\mathrm{g}}}\right) \mathrm{e}^{A_{3}\left(1 / T_{\mathrm{R}}-1 / T\right)},
$$

where $T$ is temperature, $t$ is time, $s$ is sphericity, $A_{1}, A_{2}$ and $A_{3}$ are coefficients, $r_{\mathrm{g}}$ is grain size, and $T_{\mathrm{R}}$ is reference temperature $(273.15 \mathrm{~K})$. The temperature gradient metamorphism used in SNOWPACK is described by Baunach and others (2001). It assumes that snow grains grow as plates, while the thickness of the plate stays constant. The length of a side of these plates is the temperature gradient metamorphism grain size in SNOWPACK. The grain growth rate is presented by Lehning and others (2002b) in the temperature gradient metamorphism as

$$
\dot{r}_{\mathrm{g}}(T)=\frac{\mathrm{a}^{2}\left(\mu_{\mathrm{L}}(t)-\frac{\mathrm{a}^{3}(t)}{\Delta z} \Delta / \mathrm{L} 2 \mathrm{~L}(t)\right)}{2 f_{\mathrm{gg}} \rho_{\mathrm{i}} r_{\mathrm{g}}(0) r_{\mathrm{g}}(t)},
$$

where $r_{\mathrm{g}}(0)$ is initial grain size, $\rho_{\mathrm{i}}$ is density of pure ice, $f_{\mathrm{gg}}$ is the adjustable geometrical factor for better approximation of the real grain shape (Baunach and others, 2001; Lehning and others, 2002b), / $\mathrm{L}_{\mathrm{L}}$ is interlayer mass, / $\mathrm{L}_{2} \mathrm{~L}$ is layer-to-layer mass, $r_{\mathrm{g}}(t)$ is actual growing grain size, $a$ is lattice constant and $z$ is snow height. Grain-size simulation of SNOWPACK has been fitted to grain-size measurements by adjusting model parameters empirically with cold laboratory experiments.

The optical grain size $\left(D_{0 s p}\right)$, which is simulated with SNOWPACK, is presented in Vionnet and others (2012) in the dendritic case as

$$
D_{0 \text { sp }}=10^{-4}[d+(1-d)(4-s)]
$$

and in the non-dendritic case as

$$
D_{0 \mathrm{sp}}=E_{\mathrm{sp}}(1-s) \max \left(4 \times 10^{-4}, \frac{E_{\mathrm{sp}}}{2}\right),
$$

where $D_{0 \text { sp }}(\mathrm{m})$ is the SNOWPACK optical grain size, $d$ is dendricity, $s$ is sphericity and $E_{\mathrm{sp}}(\mathrm{m})$ is SNOWPACK traditional grain size. Thus the $D_{0 s p}$ in the non-dendritic grains depends on $E_{\mathrm{sp}}$.

In this study, version 3.1.0 of SNOWPACK was used to simulate $E_{\mathrm{sp}}$ and $D_{0 \text { sp }}$ for winters 2011/12 and 2012/13. Air temperature, relative humidity, wind speed and direction, incoming and outgoing shortwave radiation and snow depth observations were collected from an operational weather station (WMO code 02836) operated by the FMI at the
Table 2. Summary of automated measurements used to drive the SNOWPACK model

\begin{tabular}{lcc}
\hline Measurements in Sodankylä & Unit & $\begin{array}{c}\text { Distance from IOA* } \\
\end{array}$ \\
& & $\mathrm{m}$ \\
\hline Air temperature & ${ }^{\circ} \mathrm{C}$ & 500 \\
Air relative humidity & $\%$ & 500 \\
Incoming shortwave radiation & $\mathrm{W} \mathrm{m}^{-2}$ & 500 \\
Outgoing shortwave radiation & $\mathrm{W} \mathrm{m}^{-2}$ & 500 \\
Snow depth & $\mathrm{Cm}^{\circ}$ & 500 \\
Snow temperature profile & ${ }^{\circ} \mathrm{C}$ & 0 \\
Soil temperature profile & ${ }^{\circ} \mathrm{C}$ & 0 \\
Wind speed & $\mathrm{m} \mathrm{s}^{-1}$ & 500 \\
Wind direction & ${ }^{\circ}$ & 500
\end{tabular}

*Intensive operation area.

Sodankylä Arctic Research Centre. These observations were augmented with automatic ground temperature observations and snow temperature observations close to the operational station. Incoming and outgoing longwave radiation observations were available, but the longwave radiation data contained gaps preventing their application in simulations. Therefore, only shortwave radiation data were used. In simulations for this study, SNOWPACK was driven by snow depth observations instead of precipitation data. Density of new snow was determined following Lehning and others (2002a). The data used to drive the model have $30 \mathrm{~min}$ intervals, and the data used for the simulations are listed in Table 2 and in the Appendix. The SNOWPACK model outputs the parameters of snow profiles at 60 min intervals.

SNOWPACK grain size has been compared to measured grain size and grain type in several recent studies (Schweizer and others, 2006; Rasmus and others, 2007; Hirashima and others, 2008). Rasmus and others (2007) calculated agreement scores for measured and simulated grain sizes in Finland; agreement was generally good in northern Finland, where the snowpack was more stable. On the other hand, Schweizer and others (2006) compared measured and simulated grain size for each grain type, finding no large differences between measured and simulated grain sizes. Langlois and others (2012) compared the correlation length derived from $D_{0}$ measured by InfraRed Integrating Sphere (Montpetit and others, 2012) and SNOWPACK model results, and scaled $D_{0}$ lower to fit measurements to simulations. Huang and others (2012) researched grain sizes predicted by different models. Their result was that SNOWPACK predictions for $E$ and $D_{0}$ are as good as predicted by using two other models (Flanner-Zender Grain Size Model (Flanner and Zender, 2006) and Jordan Grain Size Model (Sun and others, 1999)) which both predict the size parameters well.

\section{RESULTS}

\section{Comparison of experimental and snowpack modelled grain sizes}

Time series of $E, D_{O}$ and density profiles in Sodankylä snowpack

Profiles of $E$ and $D_{0}$ are presented in Figure 4 for a single snow pit in February. The layered structure of the snowpack was visible in both the $E$ and $D_{0}$ profiles. Generally, the magnitude of $E$ was larger than the magnitude of $D_{0}$. 


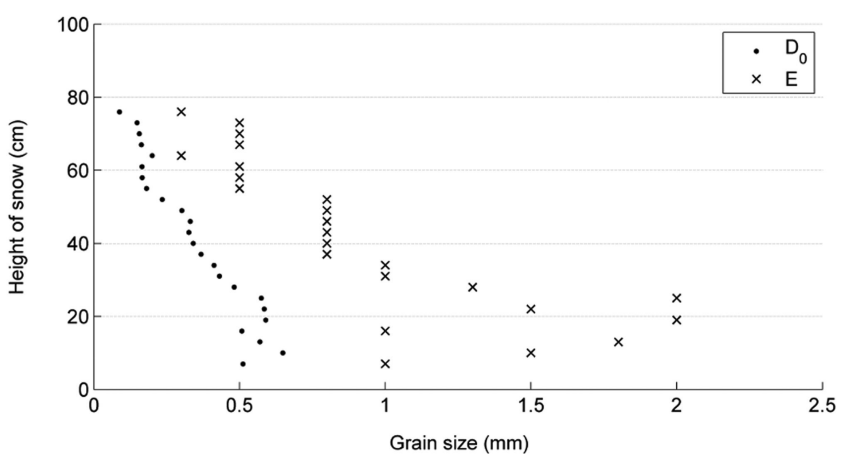

Fig. 4. $E$ (crosses) and $D_{0}$ (dots) compared using measurements made at $3 \mathrm{~cm}$ intervals for a single snow pit.

Nevertheless, both measures indicated a similar trend of increasing grain size towards the bottom snow layers. Both methods indicated relatively small variation in grain size above a snow height of $20 \mathrm{~cm}$. However, in lower layers the grain-size variability increased significantly.

Density, $E_{\mathrm{sp}}$ and $D_{0 \mathrm{sp}}$ were modelled with SNOWPACK from meteorological and radiation data as described above and in Table 2 and the Appendix. Manual density measurements are compared to SNOWPACK simulations in Figure 5.

The bias in snow thickness between manually measured and automatic observations, used as forcing for SNOWPACK simulations, was $\sim 5 \mathrm{~cm}$ during the dry snow season (Fig. 5). Both measured and simulated density values exhibit an increasing trend from snow surface towards the ground, from $50-150$ to $300-500 \mathrm{~g} \mathrm{~cm}^{-3}$ in simulated and $50-200$ to $250-450 \mathrm{~g} \mathrm{~cm}^{-3}$ for typical measured values in top and bottom layers, respectively. During the dry snow season, average densities for the 2011/12 winter were 208 and $175 \mathrm{~g} \mathrm{~cm}^{-3}$ and for the 2012/13 winter were 187 and $217 \mathrm{~g} \mathrm{~cm}^{-3}$ for measurements and simulations, respectively. During the melt season, density increased by up to $50 \%$ in both simulated and measured values. Some differences were apparent between two winter seasons: For instance, during the $2011 / 12$ winter, density was notably large during the melt season, with measured values reaching $470 \mathrm{~g} \mathrm{~cm}^{-3}$. However, for the 2012/13 winter, the maximum measured densities during the melt season were $400 \mathrm{~g} \mathrm{~cm}^{-3}$, although the density in bottom layers was larger during the dry-snow season than for the 2011/12 season.

Time series of $E, E_{\mathrm{sp}}, D_{0}$ and $D_{0 \text { sp }}$ profiles are presented in Figures 6 and 7. The range of values for $E$ was $0.25-2.75$, for $E_{\text {sp }}$ was $0-2.5$, for $D_{0}$ was $0-1.25 \mathrm{~mm}$ and for $D_{0 \text { sp }}$ was 0 $1.5 \mathrm{~mm}$. Typically, grain growth towards the bottom of the snowpack was apparent both in SNOWPACK simulations and measured data. The simulated layering profile can be compared to manually determined layering structure based on Figure 6; the measured $E$ for manually determined layers is marked on the upper edge of the respective layer. Typically, SNOWPACK simulated more layers (up to $>40$ ) than could be determined by the snow-pit observation (typically not more than ten layers). In order to allow intercomparison of $E, E_{\mathrm{sp}}, D_{0}$ and $D_{0 \text { sp }}$ in a consistent fashion, $E_{\mathrm{sp}}$ and $D_{0 \mathrm{sp}}$ were weighted with the SWE of each layer. A similar method was applied for in situ data. This was seen as a necessary process due to ambiguities in relating the many simulated layers to the relatively few layers apparent in manual observations. Furthermore, as described earlier, snow-pit observations do not represent temporal

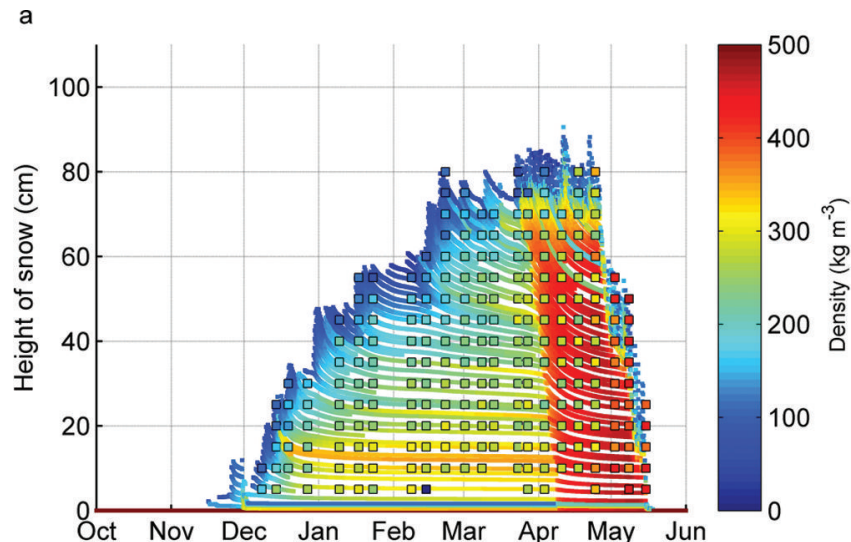

b

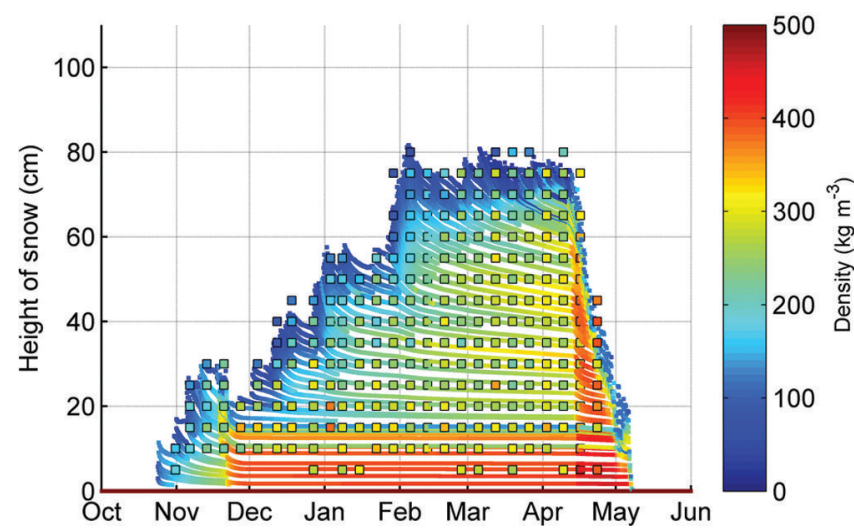

Fig 5. Snow density simulated with SNOWPACK compared to manual density measurements. Coloured boxes represent manually measured values; solid lines represent SNOWPACK simulations: (a) 2011/12; (b) 2012/13.

evolution of a discrete location but also contain the effect of spatial variability in the natural snowpack.

\section{Averaged time series of $E$ and $D_{O}$ in Sodankylä snowpack}

The time series of both manually measured and simulated $E$ and $D_{0}$ are presented in Figure 8. Root-mean-square (rms) errors, unbiased rms errors, biases and correlation coefficients $\left(R^{2}\right)$ of datasets are presented in Table 3. For the time series of $E$ and $E_{\mathrm{sp}}$ in winter $2011 / 12, R^{2}$ was 0.56 and the bias $0.12 \mathrm{~mm}$. For winter 2012/13 the variations were larger (with a bias of $0.26 \mathrm{~mm}$ ) and the $R^{2}$ was $0.36 . R^{2}$ during January-March was 0.91 and 0.28 during the first and second winters, respectively. $R^{2}$ was 0.14 and 0.54 in October-December, and 0.20 and 0.32 in the melt season of the same two seasons respectively.

$D_{0 \text { sp }}$ and $D_{0}$ trends were similar for both winters, and $R^{2}$ for the whole season was 0.75 for both seasons. During January-March 2012, $R^{2}$ was 0.42 , and during JanuaryMarch 2013, 0.76. $R^{2}$ was 0.27 and 0.94 respectively in the melting seasons and 0.79 in October-December 2012. However, $D_{0 \text { sp }}$ was constantly larger than $D_{0}$. Therefore, the bias and rms error between $D_{0}$ and $D_{0 s p}$ were larger than between $E$ and $E_{\mathrm{sp}}$.

A linear scaling factor $\beta_{\mathrm{sp}}$ describing the ratio between measured and simulated grain size can be defined so that

$$
D=\beta_{\mathrm{sp}} D_{\mathrm{sp}}
$$

where $D$ is measured grain size and $D_{\mathrm{sp}}$ is simulated grain 
a

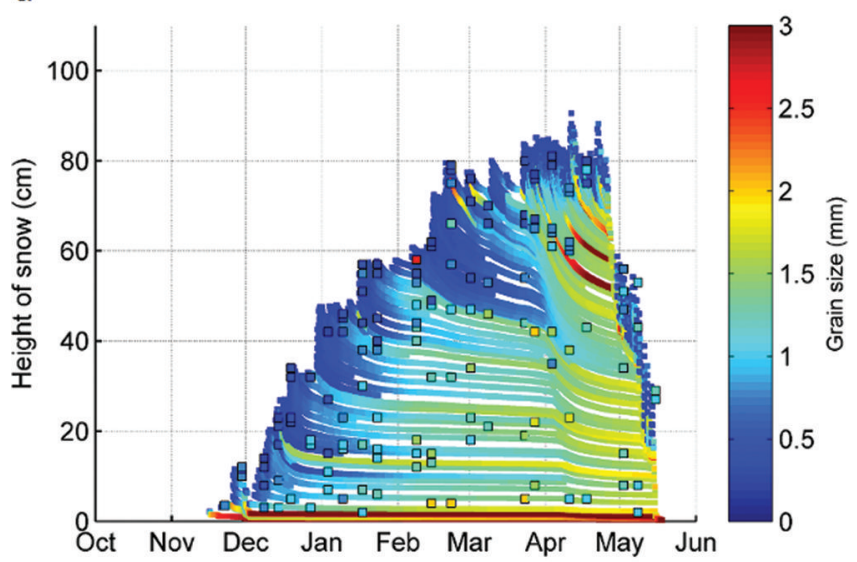

b

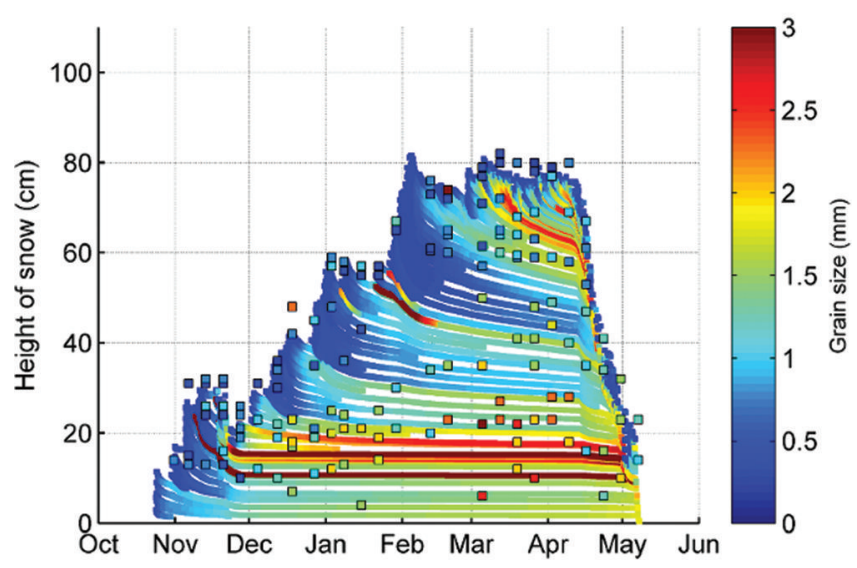

Fig. 6. SNOWPACK simulation of $E_{\mathrm{sp}}$ compared to manual measurements of $E$. Coloured boxes represent manually measured values; solid lines represent SNOWPACK simulations: (a) 2011/12; (b) $2012 / 13$

size. Values for $\beta_{\mathrm{sp}}$ and standard deviations are presented in Table 4 and Figure 9 for the two snow seasons. Average scaling factors between the two years were within 0.1 of each other on average. Considering both winters, the scaling factor, $\beta_{D 0 \text { sp }}$, between measured $D_{0}$ and simulated $D_{0 \text { sp }}$ was 2.1 , and $\beta_{E \mathrm{sp}}$ between measured $E$ and simulated $E_{\mathrm{sp}}$ was 1.2.

Table 3. Correlation coefficient $\left(R^{2}\right)$, bias, rms error and unbiased rms error between measured and SNOWPACK simulated grain sizes. Grain sizes are defined in Table 1

\begin{tabular}{lcc}
\hline & $E_{\mathrm{sp}}$ & $D_{0 \mathrm{sp}}$ \\
\hline$R^{2}$ & & \\
$E$ & 0.47 & 0.38 \\
$D_{0}$ & 0.69 & 0.74 \\
Bias & & \\
$E(\mathrm{~mm})$ & 0.19 & 0.01 \\
$D_{0}(\mathrm{~mm})$ & 0.71 & 0.50 \\
rms error & & \\
$E(\mathrm{~mm})$ & 0.37 & 0.38 \\
$D_{0}(\mathrm{~mm})$ & 0.72 & 0.53 \\
Unbiased rms error & & \\
$E(\mathrm{~mm})$ & 0.32 & 0.38 \\
$D_{0}(\mathrm{~mm})$ & 0.14 & 0.16 \\
\hline
\end{tabular}

a

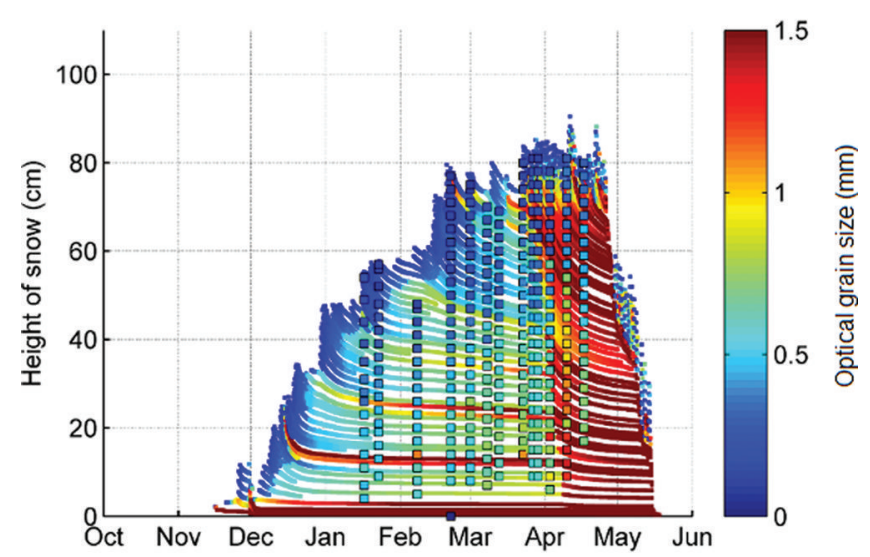

b

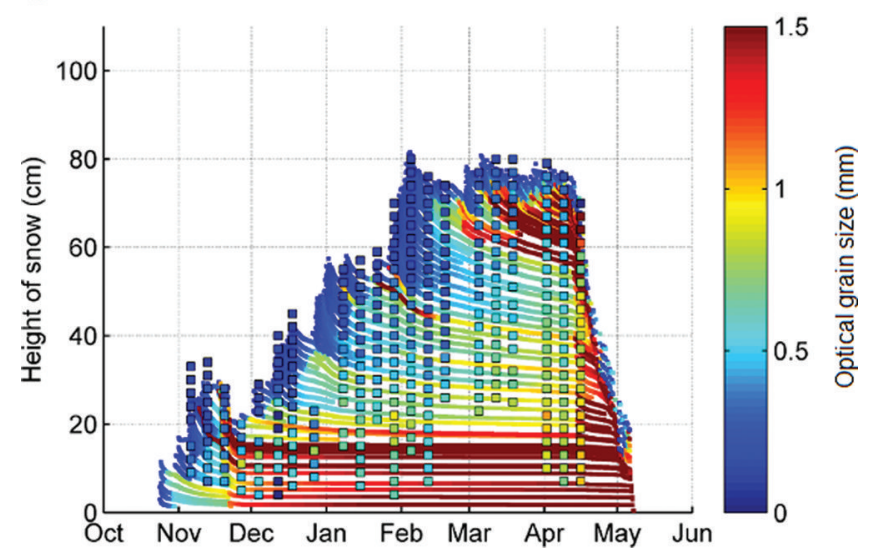

Fig. 7. SNOWPACK simulation of $D_{0 s p}$ compared to manual measurements of $D_{0}$ for snow pit 14 February 2013. Coloured boxes represent manually measured values; solid lines represent SNOWPACK simulations: (a) 2011/12; (b) 2012/13,

The standard deviations were 0.42 and 0.36 respectively. $\beta_{\text {Esp }}$ varied between 0.8 and 2.1 over both winters. $\beta_{\text {Esp }}$ was more stable during the first winter than the second, with values in the range $0.9-2.3$ compared to $0.8-1.8$ for the first and second winters, respectively. $\beta_{E s p}$ was largest during October-December and the late melting season, reaching

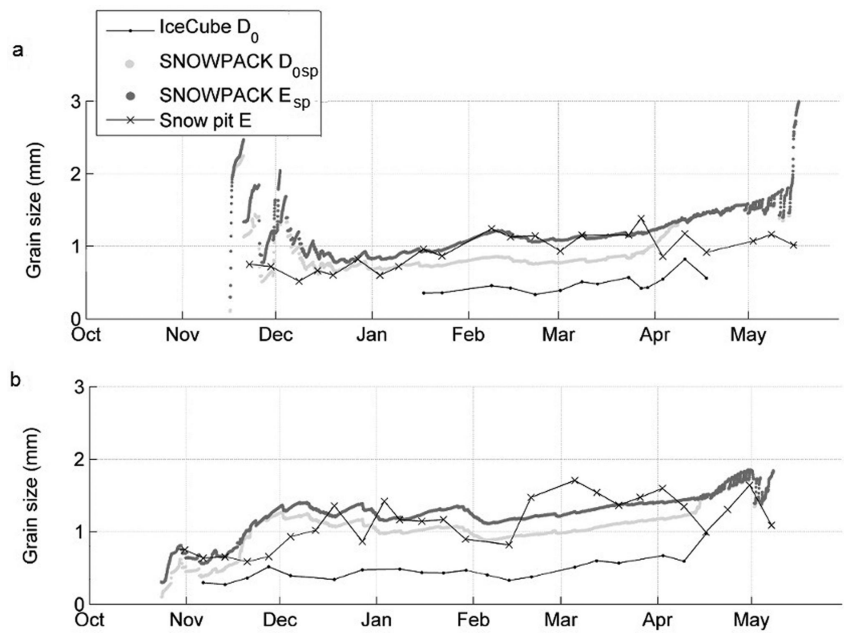

Fig. 8. Time series of measured $E$ and $D_{0}$ and SNOWPACK simulated $E_{\text {sp }}$ and $D_{\text {osp. }}$ (a) 2011/12; (b) 2012/13. 

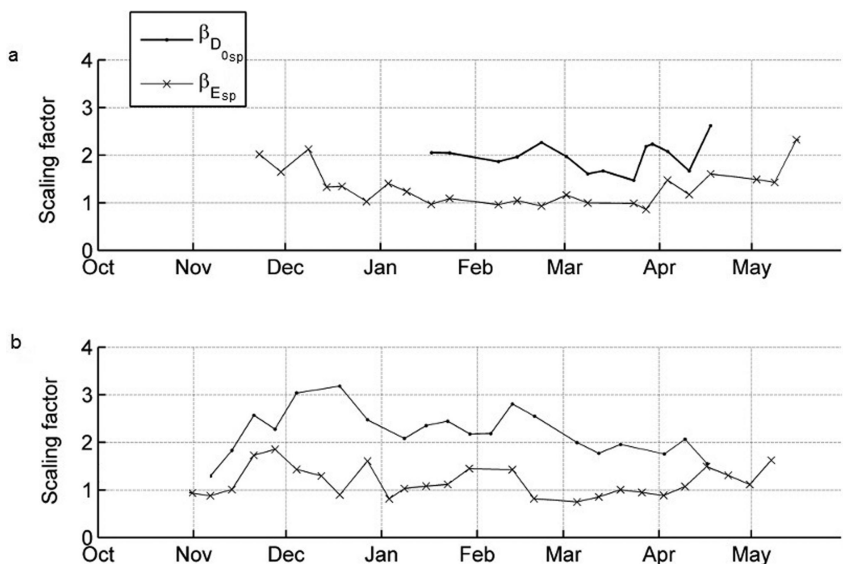

Fig. 9. Time series of scaling factors $\beta_{E s p}$ and $\beta_{D 0 \text { sp }}$ between measured $E$ and $D_{0}$ and SNOWPACK simulated $E_{\mathrm{sp}}$ and $D_{\text {Osp }}$ : (a) $2011 / 12$; (b) 2012/13.

values up to 2.3. In January-March, $\beta_{E s p}$ was 1.1 on average. Also $\beta_{D 0 \text { sp }}$ was more variable during the second winter (range 1.3-3.2) than the first (range 1.8-2.8). For $\beta_{D 0 \text { sp }}$ there was no clear seasonally related trend, but measurements in December 2012 required the largest $\beta_{D 0 \text { sp }}$ (average 3.1) while measurements in the 2013 melting season required the smallest $\beta_{D 0 \text { sp }}$ (average 1.75). In January-March, $\beta_{D 0 \text { sp }}$ was $\sim 2$.2. It can also be noticed that trends of $\beta_{D 0 \text { sp }}$ and $\beta_{E s p}$ were similar during the second winter.

\section{Sources of measurement errors}

Several factors contribute to the uncertainty of estimates of $E$, including random errors arising from preparation of the snow sample, and systematic errors arising from the estimation process itself. Errors are mainly caused by layer definition in the field, placing grains in the reference plate from the snowpack, unsuccessful photographing, failure to distinguish the single grains in the macro-photograph, failure to measure the size of a grain using a $1 \mathrm{~mm}$ reference scale or choosing the typical average grain in the macro-photograph. Other contributions to the error may be made by (1) the snow structure being disturbed when a sample of grains is placed on the reference plate, and (2) separation of the grain boundaries in the macrophotographs not always being clear.

Determining the layered stratification of the snowpack was an important aspect of the snow-pit measurement, because $E$ may vary both horizontally and vertically. However, the process was also subject to observer error.

Table 4. The scaling factor beta between measured and SNOWPACK simulaled grain sizes. $\beta_{E s p}$ is for traditional grain size $E$, and $\beta_{D 0 \text { sp }}$ is for optical grain size $D_{0}$. Standard deviations (std) are also presented

\begin{tabular}{lccc}
\hline & $2011-13$ & $2011 / 12$ & $2012 / 13$ \\
\hline$\beta_{\text {Esp }}$ & 1.24 & 1.16 & 1.3 \\
$\operatorname{std}\left(\beta_{\text {Esp }}\right)$ & 0.36 & 0.31 & 0.39 \\
$\beta_{D 0 \text { sp }}$ & 2.11 & 2.21 & 1.97 \\
$\operatorname{std}\left(\beta_{D 0 \text { sp }}\right)$ & 0.42 & 0.47 & 0.30 \\
\hline
\end{tabular}

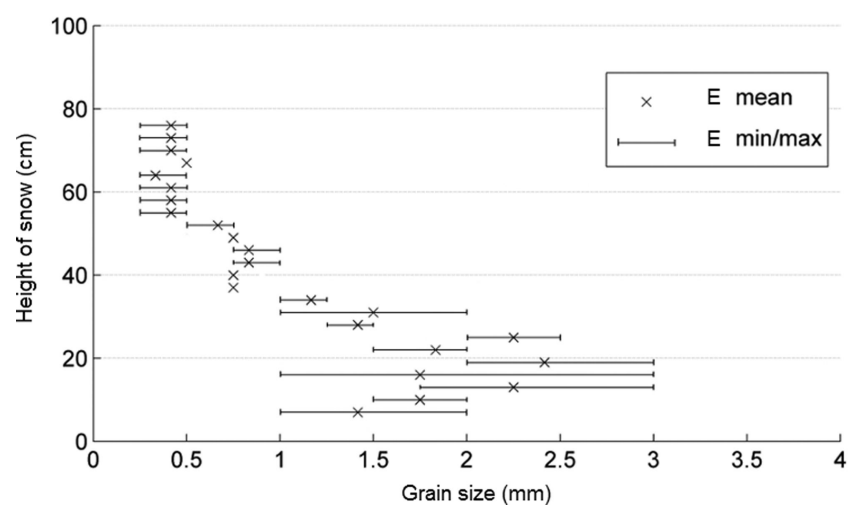

Fig. 10. An example of observer-related errors in $E$ estimations. The macro-photographs taken by $3 \mathrm{~cm}$ intervals were analysed separately by three observers; the mean value of $E$ (crosses) is marked with error bars between minimum and maximum values.

The method applied for manual layer definition has been described above. Separation of layers was occasionally difficult because differences between the layers were not always clear. An alternative instrument for the definition of snow layer boundaries is the Snow Micro Penetrometer (SMP) (Pielmeier and Schneebeli, 2003), which may allow more objective separation of the layering structure.

An example of comparison for $E$ estimations made by three observers from the same photographs is determined in Figure 10. Estimation of $E$ was made from samples taken at intervals of $3 \mathrm{~cm}$, in order to acquire more samples for comparison, and on the other hand, in order to compare with $D_{0}$ from the same snow sample. The snow pit chosen for comparison included several layers and snow types. The difference between estimations was largest at the bottom of the snowpack, where the sample contained a large scale of different grain sizes (Fig. 3). Even if all the grains in the photograph were almost the same size, there was a potential error of up to $0.25 \mathrm{~mm}$ (the precision of our estimation). More comparative data are needed for a more complete error analysis of $E$.

The errors in the IceCube measurement were a sum of random errors originating from the sampling process as well as systematic errors in instrument calibration. Preparation of the samples for the IceCube instrument involved several uncertainties caused by the compaction level of the snow in the sample holder (reflection from the bottom of the sample holder) and the sample surface smoothness (reflection from the sample surface). The errors in instrument calibration were caused by the cleanness of calibration spectralons (shade of the spectralons) and the descent temperature of the instrument and laser (power of the laser). Additional errors were caused by instrument properties. For example, scattering from grains below the sample surface resulted in underestimation of the reflectance, which appeared to be reduced by the limited field of view (Gallet and others, 2009). Moreover, the radiation penetration depth depends on snow density, which was usually $\sim 1 \mathrm{~cm}$; however, radiation did not penetrate the calibration spectralon plates as porous snow, which increased the amount of reflected radiation and worsened the accuracy of the calibration.

A total of 27 measurements included IceCube calibration data before and after the measurement. The average 
difference in $D_{0}$ between two calibrations was $0.044 \mathrm{~mm}$. The reflectance data of the largest and smallest differences between calibrations were used to derive $D_{0}$ in Figure 11. The largest difference (average from pit) was $0.113 \mathrm{~mm}$ on 10 April 2012, and the smallest average difference (average from pit) was $0.001 \mathrm{~mm}$ on 12 March 2013. Root-meansquare errors between these calibrations were $0.121 \mathrm{~mm}$ and $0.0025 \mathrm{~mm}$ respectively. Contrary to expectation, the largest differences in $D_{0}$ were between very poor and good calibrations, and the smallest were between good and poor calibrations, when the above scale is used. The average difference between $D_{0}$ of two calibrations made on the same day was still $<0.05 \mathrm{~mm}$

\section{DISCUSSION}

The magnitude of $E$ was clearly larger than $D_{0}$ in both the measured and simulated cases. However, the magnitude difference between $E_{\mathrm{sp}}$ and $D_{0 \mathrm{sp}}$ was not as large as between $E$ and $D_{0}$. Underestimation of $D_{0}$ may result partly from a lack of measurements from the bottom of the snowpack. Previous results also scaled $D_{0 \text { sp }}$ lower than in this study (Langlois and others, 2012). The best correlation (from $R^{2}$, bias rms error and unbiased rms error) was between $D_{0}$ and $D_{0 \mathrm{sp}}$ and then $E$ and $E_{\mathrm{sp}}$. The average scaling factor $\beta_{E \mathrm{sp}}$ varied $13 \%$ from one winter to another, and $\beta_{D 0 \text { sp }}$ was within $11 \%$. Standard deviations of yearly scaling factors were in the range $0.3-0.5$.

According to our results, SNOWPACK simulations of $E_{\mathrm{sp}}$ and $D_{\text {Osp }}$ showed the best agreement with field measurements during January-March conditions. For early winter in November and the snowmelt season in April and May, $E_{\mathrm{sp}}$ and $D_{0 \text { sp }}$ varied most, and a clear disconnect from field measurements was also apparent. During October-December, only a few snow layers were identified in field measurements; thus the variability in individual observations of $E$ and $D_{0}$ affected the overall bulk average and the calculated average scaling factor. Overestimation of SNOWPACK density also affected the weak correlation of $E$ and $D_{0}$ measurements with simulations during the melt season. Furthermore, measurements of $E$ and $D_{0}$ also exhibit more uncertainties during the melt season in wet snow conditions.

Determination of layers, placing the grains in the reference plate and observer-related estimation causes the largest errors in $E$. Choosing the average $E$ from the macrophotograph is the most sensitive part for error estimation. A comparison of estimates from three observers of the same macro-photographs indicated errors up to $1 \mathrm{~mm}$. $D_{0}$, measured using the IceCube instrument, however, was less sensitive to observer-related errors than $E$ estimates, but several stages of the measurement process (sampling, calibration of original values, deriving $D_{0}$ from SSA) may still result in inaccuracies. The light newly fallen snow (density $\sim 50 \mathrm{~g} \mathrm{~L}^{-1}$ ) had to be compacted in the sample holder, and the quality of the sample was affected by different sampling techniques, smoothness of the sample surface, etc. The calibration-related error was relatively small (average $0.05 \mathrm{~mm}$; maximum $0.12 \mathrm{~mm}$ ). Error is very small because calibrations are made during the same measurement occasion. Calibration errors were further reduced by cleaning calibration spectralons, and stabilizing the instrument and laser temperatures before the calibration.

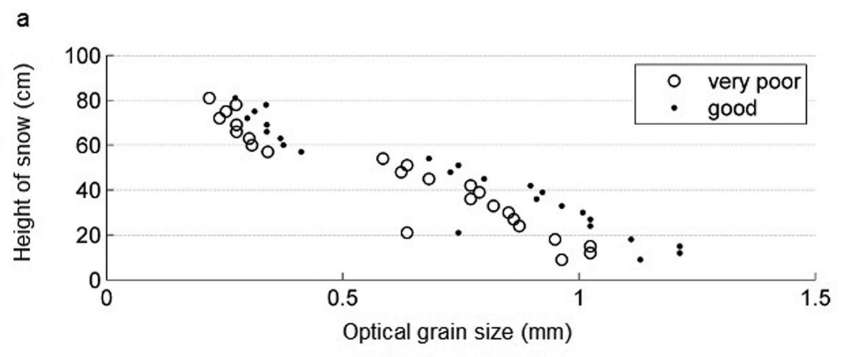

b

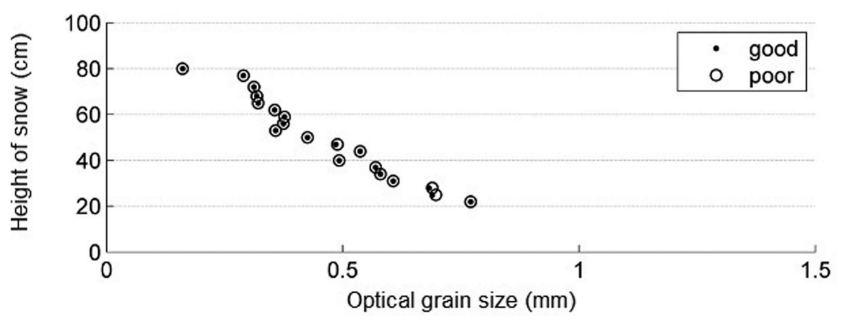

Fig. 11. The effect of repeated calibration of the SSA measurements on $D_{0}$. The same IceCube measurement is calibrated twice. On 10 April 2012, the mean difference between very poor (unfilled circles) and good (dots) calibrations of $D_{0}$ was $0.113 \mathrm{~mm}$; on 12 March 2013 the difference between good (dots) and poor (unfilled circles) calibrations of $D_{0}$ was $0.001 \mathrm{~mm}$.

\section{CONCLUSIONS}

A description of the snow microstructure is essential for physical snow models and radiative transfer models. A typical measure applied as a proxy indicator of snow microstructure has been the grain size $(E)$. However, there are several ambiguities related to defining and measuring $E$. An alternative parameter describing snow microstructure, the optical grain size $\left(D_{0}\right)$, can be derived from SSA measurements (Gallet and others, 2009). However, the definition of $D_{0}$ is based on optics, and its measurement is based on optical reflection from snow, which is not directly related, for example, to the scattering behaviour of radiation at microwave frequencies. On the other hand, empirical relations between $E$ and the propagation of microwaves have been established in the past (Hallikainen and others, 1987). Physical snow models such as SNOWPACK are important for global derivation of snow properties that are difficult to observe in the field (e.g. grain size), for remotesensing applications and hazard prediction systems. Therefore, a good correlation of manual measurements with the model is essential.

The main objective of the study was to compare $E$ and $D_{0}$ to $E_{\mathrm{sp}}$ and $D_{0 \mathrm{sp}}$. Another objective was to define measurement errors of $E$ and $D_{0}$. The measurements were made during the 2011/12 and 2012/13 winters in Sodankylä.

Layers simulated with SNOWPACK were not directly comparable with the manually determined layering structure, as simulation typically produced more layers with also a differing density profile. Furthermore, collected field data also exhibited the effects of spatial variability in natural snow. Therefore, averaged and weighted values for the whole snowpack were used in this study for intercomparison of measured and simulated values.

The temporal variation of measured and simulated values was similar in the time series (Fig. 8); however, in the first winter the average correlation was better. The largest difference between measured and simulated values occurred 
in October-December and during the melting season in April and May. The magnitude of $D_{0 s p}$ was approximately twice as large as $D_{0}$, while the magnitude of $E$ was almost the same for measured and simulated values (Table 3; Fig. 9). Calculated $R^{2}$ values were best between the same respective measured and simulated parameters, even though the magnitude of $D_{0 \text { sp }}$ was closer to $E$ than $D_{0}$ (Table 4).

The largest uncertainties in both $E$ estimations and $D_{0}$ measurements were estimated to occur in the bottom layer of the snowpack, where the grains were large and loose. The IceCube calibration error was $0.05 \mathrm{~mm}$ on average. The effect of other errors (sampling method, sample surface smoothness and observer) on $D_{0}$ was $<0.1 \mathrm{~mm}$ in our preliminary unpublished results. $E$ for an average grain was estimated to the nearest $0.25 \mathrm{~mm}$. The magnitude of error in $E$ was suspected to be in the millimetre range (Fig. 11).

This study suggests that SNOWPACK was able to simulate with reasonable accuracy the magnitude and trend of traditional grain-size profiles for boreal forest/taiga snow in midwinter. In the case of optical grain size, SNOWPACK simulations exhibited a notably large bias compared to measured values; however, the correlation between measured and simulated values exceeded that of the classical grain size.

\section{ACKNOWLEDGEMENTS}

We thank the WSL Institute for Snow and Avalanche Research SLF and especially Mathias Bavay and Martin Schneebeli for the opportunity to use the SNOWPACK model. We also thank the staff of FMI Arctic Research Centre in Sodankylä for performing the in situ measurements.

\section{REFERENCES}

Adams EE and Brown RL (1982) A model for crystal development in dry snow. Geophys. Res. Lett., 9(11), 1287-1289 (doi: 10.1029/ GL009i011p01287)

Arnaud L and 7 others (2011) Measurement of vertical profiles of snow specific surface area with a $1 \mathrm{~cm}$ resolution using infrared reflectance: instrument description and validation. J. Glaciol., 57(201), 17-29 (doi: 10.3189/002214311795306664)

Baunach T, Fierz C, Satyawali PK and Schneebeli M (2001) A model for kinetic grain growth. Ann. Glaciol., 32, 1-6 (doi: 10.3189/172756401781819427)

Brown RD (2000) Northern Hemisphere snow cover variability and change, 1915-97. J. Climate, 13(7), 2339-2355 (doi: 10.1016/ S0165-232X(01)00032-5)

Brown RL, Edens MQ and Barber M (1999) Mixture theory of mass transfer based upon microstructure. Defence Sci. J., 49(5), 393-409

Brown RL, Satyawali PK, Lehning M and Bartelt P (2001) Modeling the changes in microstructure during metamorphism. Cold Reg. Sci. Technol., 33(2-3), 91-101 (doi: 10.1016/S0165-232X(01) 00032-5)

Brun E, David P, Sudul M and Brunot G (1992) A numerical model to simulate snow-cover stratigraphy for operational avalanche forecasting. J. Glaciol., 38(128), 13-22

Chang ATC, Foster JL, Hall DK, Rango A and Hartline BK (1982) Snow water equivalent estimation by microwave radiometry. Cold Reg. Sci. Technol., 5(3), 259-267 (doi: 10.1016/0165232X(82)90019-2)

Chen S and Baker I (2010) Evolution of individual snowflakes during metamorphism. J. Geophys. Res., 115(D21), D21114 (doi: 10.1029/2010JD014132)
Colbeck SC (1982) An overview of seasonal snow metamorphism. Rev. Geophys. Space Phys., 20(1), 45-61 (doi: 10.1029/ RG020i001p00045)

Colbeck SC (1991) The layered character of snow covers. Rev. Geophys., 29(1), 81-96 (doi: 10.1029/90RG02351)

Colbeck SC and 7 others (1990) The international classification for seasonal snow on the ground. International Commission on Snow and Ice, International Association of Scientific Hydrology, Wallingford

De Vries DA (1963) Thermal properties of soils. In Van Wijk WR ed. Physics of plant environment. North-Holland Publishing Co., Amsterdam

Debye P, Anderson HR and Brumberger H (1957) Scattering by an inhomogeneous solid II. The correlation function and its application. J. Appl. Phys., 28(6), 679-683 (doi: 10.1063/ 1.1722830)

Domine F, Cabanes A, Taillandier AS and Legagneux L (2001) Specific surface area of snow samples determined by $\mathrm{CH}_{4}$ adsorption at $77 \mathrm{~K}$ and estimated by optical microscopy and scanning electron microscopy. Environ. Sci. Technol., 35(4), 771-780 (doi: 10.1021/es001168n)

Domine F, Salvatori R, Legagneux L, Salzano R, Fily M and Casacchia $R$ (2006) Correlation between the specific surface area and the short wave infrared (SWIR) reflectance of snow. Cold Reg. Sci. Technol., 46(1), 60-68 (doi: 10.1016/j.coldregions. 2006.06.002)

Domine $\mathrm{F}$ and 7 others (2008) Snow physics as relevant to snow photochemistry. Atmos. Chem. Phys., 8(2), 171-208 (doi: 10.5194/acp-8-171-2008)

Dozier J and Painter TH (2004) Multispectral and hyperspectral remote sensing of alpine snow properties. Annu. Rev. Earth Planet. Sci., 32, 465-494 (doi: 10.1146/annurev.earth.32. 101802.120404)

Dozier J, Davis RE and Perla R (1987) On the objective analysis of snow microstructure. IAHS Publ. 162 (Symposium at Davos 1986 - Avalanche Formation, Movement and Effects), 49-59

Fierz C and 8 others (2009) The international classification for seasonal snow on the ground. (IHP Technical Documents in Hydrology 83) UNESCO-International Hydrological Programme, Paris

Flanner MG and Zender CS (2006) Linking snowpack microphysics and albedo evolution. J. Geophys. Res., 111(D12), D12208 (doi: 10.1029/2005JD006834)

Flin F and 9 others (2005) Adaptive estimation of normals and surface area for discrete 3-D objects: application to snow binary data from x-ray tomography. IEEE Trans. Image Process., 14(5), 585-596 (doi: 10.1109/TIP.2005.846021)

Gallet J-C, Domine F, Zender CS and Picard G (2009) Measurement of the specific surface area of snow using infrared reflectance in an integrating sphere at 1310 and $1550 \mathrm{~nm}$. Cryosphere, 3(2), 167-182 (doi: 10.5194/tc-3-167-2009)

Giddings JC and LaChapelle E (1961) Diffusion theory applied to radiant energy distribution and albedo of snow. J. Geophys. Res., 66(1), 181-189 (doi: 10.1029/JZ066i001p00181)

Grenfell TC and Warren SG (1999) Representation of a nonspherical ice particle by a collection of independent spheres for scattering and absorption of radiation. J. Geophys. Res., 104(D24), 31 697-31 709 (doi: 10.1029/2005JD005811)

Hall DK, Riggs GA and Salomonson VV (1995) Development of methods for mapping global snow cover using Moderate Resolution Imaging Spectroradiometer (MODIS) data. Remote Sens. Environ., 54(2), 127-140 (doi: 10.1016/0034-4257(95) 00137-P)

Hall DK, Riggs GA, Salomonson VV, DiGirolamo N and Bayr KJ (2002) MODIS snow-cover products. Remote Sens. Environ., 83(1-2), 181-194 (doi: 10.1016/S0034-4257(02)00095-0)

Hallikainen MT, Ulaby FT and Van Deventer TE (1987) Extinction behavior of dry snow in the 18 - to $90-\mathrm{GHz}$ range. IEEE Trans. Geosci. Remote Sens., 25(6), 737-745 (doi: 10.1109/ TGRS.1987.289743) 
Hirashima H, Nishimura K, Yamaguchi S, Sato A and Lehning M (2008) Avalanche forecasting in a heavy snowfall area using the snowpack model. Cold Reg. Sci. Technol., 51(2-3), 191-203 (doi: 10.1016/j.coldregions.2007.05.013)

Huang C, Margulis SA, Durand MT and Musselman KN (2012) Assessment of snow grain-size model and stratigraphy representation impacts on snow radiance assimilation: forward modeling evaluation. IEEE Trans. Geosci. Remote Sens., 50(11), 4551-4564 (doi: 10.1109/TGRS.2012.2192480)

Jin Y-Q (1993) Electromagnetic scattering modelling for quantitative remote sensing. World Scientific, Singapore

Kokhanovsky AA and Zege EP (2004) Scattering optics of snow. Appl. Opt., 43(7), 1589-1602 (doi: 10.1364/AO.43.001589)

Langlois A and 8 others (2010) On the relationship between snow grain morphology and in-situ near infrared calibrated reflectance photographs. Cold Reg. Sci. Technol., 61(1), 34-42 (doi: 10.1016/j.coldregions.2010.01.004)

Langlois A, Royer A, Derksen C, Montpetit B, Dupont F and Goïta K (2012) Coupling the snow thermodynamic model SNOWPACK with the microwave emission model of layered snowpacks for subarctic and arctic snow water equivalent retrievals. Water Resour. Res., 48(12), W12524 (doi: 10.1029/2012WR012133)

Legagneux L, Cabanes A and Domine F (2002) Measurement of the specific surface area of 176 snow samples using methane adsorption at 77 K. J. Geophys. Res., 107(D17), 4335 (doi: 10.1029/2001JD001016)

Lehning M, Bartelt P, Brown B, Fierz C and Satyawali P (2002a) A physical SNOWPACK model for the Swiss avalanche warning. Part II: snow microstructure. Cold Reg. Sci. Technol., 35(3), 147-167 (doi: 10.1016/S0165-232X(02)00072-1)

Lehning M, Bartelt P, Brown B and Fierz C (2002b) A physical SNOWPACK model for the Swiss avalanche warning. Part III: meteorological forcing, thin layer formation and evaluation. Cold Reg. Sci. Technol., 35(3), 169-184 (doi: 10.1016/S0165232X(02)00072-1)

Martinec J and Rango A (1986) Parameter values for snowmelt runoff modelling. J. Hydrol., 84(3-4), 197-219 (doi: 10.1016/ 0022-1694(86)90123-X)

Matzl M and Schneebeli M (2006) Measuring specific surface area of snow by near-infrared photography. J. Glaciol., 52(179), 558-564 (doi: 10.3189/172756506781828412)

Matzl M and Schneebeli M (2010) Stereological measurement of the specific surface area of seasonal snow types: comparison to other methods, and implications for mm-scale vertical profiling. Cold Reg. Sci. Technol., 64(1), 1-8 (doi: 10.1016/j.coldregions.2010.06.006)

Mätzler C (2002) Relation between grain-size and correlation length of snow. J. Glaciol., 48(162), 461-466 (doi: 10.3189/ 172756502781831287)

Mätzler C and Wiesmann A (1999) Extension of the microwave emission model of layered snowpacks to coarse-grained snow. Remote Sens. Environ., 70(3), 317-325 (doi: 10.1016/S00344257(99)00047-4)

Maurer EP, Rhoads JD, Dubayah RO and Lettenmaier D (2003) Evaluation of the snow-covered area data product from MODIS. Hydrol. Process., 17(1), 59-71 (doi: 10.1002/hyp.1193)

Mognard NM (2003) Global snow-cover evolution from twenty years of satellite passive microwave data. In Proceedings of International Geoscience and Remote Sensing Symposium (IGARSS 2003), 21-25 July 2003, Toulouse, France, Vol. 4. Institute of Electrical and Electronics Engineers, Piscataway, NJ, 2838-2840

Montpetit B and 8 others (2012) New shortwave infrared albedo measurements for snow specific surface area retrieval. J. Glaciol., 58(211), 941-952 (doi: 10.3189/2012JoG11J248)

Painter TH, Molotch NP, Cassidy M, Flanner M and Steffen K (2007) Contact spectroscopy for determination of stratigraphy of snow optical grain size. J. Glaciol., 53(180), 121-127 (doi: 10.3189/172756507781833947)

Picard G, Arnaud L, Domine F and Fily M (2009) Determining snow specific surface area from near-infrared reflectance measurements: numerical study of the influence of grain shape. Cold Reg. Sci. Technol., 56(1), 10-17 (doi: 10.1016/ j.coldregions.2008.10.001)

Pielmeier C and Schneebeli M (2003) Stratigraphy and changes in hardness of snow measured by hand, rammsonde and snow micro penetrometer; a comparison with planar sections. Cold Reg. Sci. Technol., 37(3), 393-405 (doi: 10.1016/S0165-232X (03)00079-X)

Pirinen P, Simola H, Aalto J, Kaukoranta J-P, Karlsson P and Ruuhela R (2012) Climatological statistics of Finland 19812012. (Report No. 2012-1) Finnish Meteorological Institute, Helsinki

Pulliainen J and Hallikainen M (2001) Retrieval of regional snow water equivalent from space-borne passive microwave observations. Remote Sens. Environ., 75(1), 76-85 (doi: 10.1016/ S0034-4257(00)00157-7)

Pulliainen JT, Grandell J and Hallikainen MT (1999) HUT snow emission model and its applicability to snow water equivalent retrieval. IEEE Trans. Geosci. Remote Sens., 37(3), 1378-1390 (doi: 10.1109/36.763302)

Rasmus S, Gronholm S, Lehning T, Rasmus $M$ and Kulmala $M$ (2007) Validation of the SNOWPACK model in five different snow zones in Finland. Boreal Environ. Res., 12(4), 467-488

Roy V, Goïta K, Royer R, Walker AE and Goodison BE (2004) Snow water equivalent retrieval in a Canadian boreal environment from microwave measurements using the HUT snow emission model. IEEE Trans. Geosci. Remote Sens., 42(9), 1850-1859 (doi: 10.1109/TGRS.2004.832245)

Schweizer J, Bellaire S, Fierz C, Lehning M and Pielmeier C (2006) Evaluating and improving the stability predictions of the snow cover model SNOWPACK. Cold Reg. Sci. Technol., 46(1), 52-59 (doi: 10.1016/j.coldregions.2006.05.007)

Shaffrey LC and 25 others (2009) U.K. HiGEM: the new UK highresolution global environment model - model description and basic evaluation. J. Climate, 22(8), 1861-1896 (doi: 10.1175/ 2008JCLI2508.1)

Stogryn A (1986) A study of the microwave brightness temperature of snow from the point of view of the strong fluctuation theory. IEEE Trans. Geosci. Remote Sens., 24(2), 220-231 (doi: 10.1109/TGRS.1986.289641)

Sturm M, Morris K and Massom R (1998) The winter snow cover of the West Antarctic pack ice: its spatial and temporal variability. In Jeffries MO ed. Antarctic sea ice: physical processes, interactions and variability. (Antarctic Research Series 74) American Geophysical Union, Washington, DC, 1-18

Sun S, Jin J and Xue Y (1999) A simple snow-atmosphere-soil transfer model. J. Geophys. Res., 104(D16), 19 587-19597 (doi: 10.1029/1999JD900305)

Tedesco M and Kim EJ (2006) Intercomparison of electromagnetic models for passive microwave remote sensing of snow. IEEE Trans. Geosci. Remote Sens., 44(10), 2654-2666 (doi: 10.1109/ TGRS.2006.873182)

Tsang $L$ and Kong JA (1981) Scattering of electromagnetic waves from random media with strong permittivity fluctuations. Radio Sci., 16, 303-320 (doi: 10.1029/RS016i003p00303)

Tsang L, Kong JA and Shin RT (1985) Theory of microwave remote sensing. Wiley, New York

Vionnet $V$ and 7 others (2012) The detailed snowpack scheme Crocus and its implementation in SURFEX v7.2. Geosci. Model Dev., 5(3), 773-791 (doi: 10.5194/gmd-5-773-2012)

Wiesmann A and Mätzler C (1999) Microwave emission model of layered snowpacks. Remote Sens. Environ., 70(3), 307-316 (doi: 10.1016/S0034-4257(99)00046-2)

Wiesmann A, Mätzler C and Weise T (1998) Radiometric and structural measurements of snow samples. Radio Sci., 33(2), 273-289 (doi: 10.1029/97RS02746)

Wiscombe WJ and Warren SG (1980) A model for the spectral albedo of snow. I. Pure snow. J. Atmos. Sci., 37(12), 2712-2733 (doi: 10.1175/1520-0469(1980)037<2712:AMFTSA>2.0.CO;2) 


\section{APPENDIX}

Table 5. SNOWPACK.ini file parameters

\begin{tabular}{|c|c|c|}
\hline Data step length & $30 \mathrm{~min}$ & \\
\hline Calculation step length & $15 \mathrm{~min}$ & \\
\hline Height of meteo values & $2.0 \mathrm{~m}$ & \\
\hline Height of wind value & $22.0 \mathrm{~m}$ & \\
\hline $\begin{array}{l}\text { Enforce measured snow } \\
\text { heights }\end{array}$ & True & \\
\hline SW mode & 2 & $\begin{array}{c}\text { Incoming and reflected } \\
\text { shortwave radiation are both } \\
\text { measured }\end{array}$ \\
\hline Neutral & 1 & $\begin{array}{c}\text { Force Monin-Obukhov } \\
\text { formulation to assume neutral } \\
\text { conditions }\end{array}$ \\
\hline Canopy & False & Open area \\
\hline Measure TSS & False & $\begin{array}{l}\text { Measured surface temperature } \\
\text { not available }\end{array}$ \\
\hline Change BC & False & \\
\hline Incoming longwave & False & \\
\hline Snow redistribution & True & \\
\hline SNP SOIL & True & Soil layers defined \\
\hline Soil flux & False & \\
\hline Geo heat & 0.06 & \\
\hline Advanced settings & $\begin{array}{l}\text { Default variant, } \\
\text { default settings }\end{array}$ & \\
\hline
\end{tabular}

Table 6. SNOWPACK.sno file parameters

\begin{tabular}{|c|c|c|}
\hline Latitude & 7571768 & \multirow[t]{5}{*}{ Sodankylä, northern Finland } \\
\hline Longitude & 484270 & \\
\hline Altitude & $180 \mathrm{~m}$ & \\
\hline Slope Angle & $0.0^{\circ}$ & \\
\hline Slope Azi & $0.0^{\circ}$ & \\
\hline nSoilLayerData & 1 & \multirow[t]{12}{*}{$\begin{array}{c}\text { Soil homogeneous at least } \\
\text { the first } 1.5 \mathrm{~m}\end{array}$} \\
\hline nSnowLayerData & 0 & \\
\hline Bare Soil z0 & 0.02 & \\
\hline Soil Albedo & 0.2 & \\
\hline CanopyHeight & $10.0 \mathrm{~m}$ & \\
\hline CanopyLeafArealndex & 0.0 & \\
\hline CanopyDirect- & 0.0 & \\
\hline Throughfall & & \\
\hline WindScalingFactor & 1.0 & \\
\hline Profiledate & 01.08 .2011 & \\
\hline Soil layer thickness & $1.5 \mathrm{~m}$ & \\
\hline Volume fraction ice & 0.00 & \\
\hline Volume fraction water & 0.15 & \multirow[t]{3}{*}{$\begin{array}{l}\text { Calculated from automatic } \\
\text { soil moisture measurements }\end{array}$} \\
\hline Volume fraction void & 0.15 & \\
\hline Volume fraction soil & 0.7 & \\
\hline Soil density & $1700 \mathrm{~kg} \mathrm{~m}^{-3}$ & \multirow{3}{*}{$\begin{array}{c}\text { Soil approximated as } \\
\text { compact sandy soil. Values } \\
\text { estimated according to the } \\
\text { volumetric fraction of water } \\
\text { after de Vries (1963) }\end{array}$} \\
\hline Soil heat conductivity & $1.5 \mathrm{~W} \mathrm{~m}^{-1} \mathrm{~K}^{-1}$ & \\
\hline Soil specific heat & $1200 \mathrm{~J} \mathrm{~kg}^{-1} \mathrm{~K}^{-1}$ & \\
\hline
\end{tabular}

MS received 27 January 2014 and accepted in revised form 5 October 2014 